\title{
The limited importance of size-asymmetric light competition and growth of pioneer species in early secondary forest succession in Vietnam
}

\author{
Marijke van Kuijk $\cdot$ N. P. R. Anten • \\ R. J. Oomen · D. W. van Bentum · M. J. A. Werger
}

Received: 14 September 2007 / Accepted: 13 April 2008/Published online: 15 May 2008

(C) The Author(s) 2008

\begin{abstract}
It is generally believed that asymmetric competition for light plays a predominant role in determining the course of succession by increasing size inequalities between plants. Size-related growth is the product of sizerelated light capture and light-use efficiency (LUE). We have used a canopy model to calculate light capture and photosynthetic rates of pioneer species in sequential vegetation stages of a young secondary forest stand. Growth of the same saplings was followed in time as succession proceeded. Photosynthetic rate per unit plant mass $\left(P_{\text {mass }}\right.$ : mol $\mathrm{C} \mathrm{g}^{-1}$ day $\left.^{-1}\right)$, a proxy for plant growth, was calculated as the product of light capture efficiency $\left[\Phi_{\text {mass }}\right.$ : mol photosynthetic photon flux density (PPFD) $\mathrm{g}^{-1}$ day $^{-1}$ ] and LUE (mol C mol PPFD ${ }^{-1}$ ). Species showed different morphologies and photosynthetic characteristics, but their light-capturing and light-use efficiencies, and thus $P_{\text {mass }}$, did not differ much. This was also observed in the field: plant growth was not sizeasymmetric. The size hierarchy that was present from the very early beginning of succession remained for at least the first 5 years. We conclude, therefore, that in slowgrowing regenerating vegetation stands, the importance of asymmetric competition for light and growth can be much less than is often assumed.
\end{abstract}

Communicated by Robert Pearcy.

M. van Kuijk $(\bowtie) \cdot$ N. P. R. Anten · R. J. Oomen ·

D. W. van Bentum - M. J. A. Werger

Department of Plant Ecology and Biodiversity, Institute of

Environmental Biology, Utrecht University, P.O. Box 80084,

3508 TB Utrecht, The Netherlands

e-mail: marijkevankuijk@hotmail.com; m.vankuijk@uu.nl
Keywords Canopy model $\cdot$ Light capture · Photosynthesis - Regeneration - Tropical forest

\section{Introduction}

Secondary forest succession is generally described as the process in which different (groups of) species replace each other in time following a disturbance (Finegan 1984; Peña-Claros 2003). Natural forest regeneration after a disturbance is often slow or stagnates, often due to the excessive growth of shrubs or grasses (Aide et al. 1995).

In wet tropical forests light seems to play a predominant role in determining the course of succession (Denslow 1987). As secondary succession proceeds, both the height and leaf area index (LAI) of the stand increase rapidly (Swaine and Hall 1983; Uhl 1987), thereby creating an increasingly steeper gradient in photosynthetic photon flux density (PPFD, 400-700 nm) and a situation in which plants strongly compete for light.

Competition for resources can be either symmetric or asymmetric, and the degree of asymmetry can have profound consequences on the dynamics in vegetation stands (Weiner 1990; Weiner and Thomas 1986). Under conditions of symmetric competition, individuals grow in proportion to their size; in contrast, under those of asymmetric competition, larger individuals grow disproportionately faster, resulting in increased size inequality among plants (Weiner 1990). It is often assumed that competition for light is asymmetric since larger individuals shade smaller ones but not vice versa (Ford 1975; Schwinning and Weiner 1998). This in turn has led to the connotation that asymmetric competition for light is the main force shaping secondary succession in tropical forests (Huston and Smith 1987; Van Breugel 2007). 
Growth relative to size can be calculated as the product of size-dependent light capture and light-use efficiency (LUE) (Hikosaka et al. 1999; Schwinning 1996; Schwinning and Weiner 1998). Hirose and Werger (1995) introduced a model approach by which interspecific differences in light capture by grasses and herbs were related to differences in size, such as leaf area and above-ground mass. Shorter subordinate species captured similar amounts of light per unit above-ground mass $\left(\Phi_{\text {mass }}\right)$ as taller ones despite the fact that they were growing in the shade (see also Aan et al. 2006; Anten and Hirose 1999; Hirose and Werger 1995). According to the definition of Schwinning and Weiner (1998), this similarity in $\Phi_{\text {mass }}$ indicates that, contrary to what is generally assumed, light competition among these species was size-symmetric (Anten and Hirose 1998). Light-use efficiency is highly dependent on plant physiological characteristics, such as (dark) respiration, quantum yield and maximum photosynthetic rates, with the latter being dependent on leaf nitrogen $(\mathrm{N})$ content and photosynthetic $\mathrm{N}$ use efficiency (e.g. Anten and Hirose 2003; Ellsworth and Reich 1996; Hiremath 2000).

To the best of our knowledge, only one study (Selaya 2007) to date has quantified light capture and photosynthesis of individual plants in a secondary tropical forest. This researcher found that the two disproportionately fastest growing species did achieve high photosynthetic rates, but that these were not due to higher light-capturing efficiencies but to high LUE. As yet, there has been no report describing plant size-dependent light capture and LUE and their relation to plant growth over time on the same plants in a secondary tropical forest. Consequently, the degree of asymmetry of the competition for light and its importance for secondary forest succession remain unclear.

Here we quantify light competition, light use, photosynthetic rates and growth of early successional species in central Vietnam. Traditionally Vietnam is a forested country, but it has lost many of its forests as a result of wars, fires, logging and agricultural practices (Hirsch 1997); in addition, natural forest regeneration is slow (Orians and Pfeiffer 1970). Most field studies on succession have been carried out in chrono-sequences, in which sites of different ages are studied simultaneously (Selaya et al. 2007; Werger et al. 2002). Such studies are based on many assumptions regarding site history, environmental conditions and seed availability (Bakker et al. 1996). In the study reported here, we followed the same individual plants during the first 18 months of secondary succession. A slightly older vegetation stand with higher LAI and vegetation height was studied as well. Observed aboveground growth patterns of early successional species and the underlying processes in terms of light capture (morphology) and LUE (physiology) were analysed using a mechanistic approach.

\section{Methods}

Study area

The study site is located in the buffer zone of Bach $\mathrm{Ma}$ National Park in central Vietnam $\left(16^{\circ} 10^{\prime} \mathrm{N} 107^{\circ} 50^{\prime} \mathrm{E}\right)$. The park and its buffer zone were established in 1991 with a total area of 43,331 ha. It is the core of the last remaining contiguous forest belt in Vietnam, stretching from the South China Sea to the border with Laos. The area experiences high rainfall, especially from November until February (up to $8000 \mathrm{~mm}$ per year on top of Bach $\mathrm{Ma}$ mountain). There is no distinct dry season and the vegetation is evergreen (Tran and Ziegler 2001). After defoliation and destruction in the war (1965-1975), the study site was used for monoculture plantations of Acacia mangium. Part of the site (2 ha) was left fallow in 1999 and was a 5-year-old secondary forest stand at the start of this study.

\section{Species selection}

We selected four study species, all co-dominant in the stand: the shrub, Melastoma candidum (Melastomataceae), and three tree species, Mallotus microcarpus, Mallotus paniculatus and Macaranga denticulata (all Euphorbiaceae). They represented over $75 \%$ of the total plant cover at the beginning of the study period and were the only woody species present in sufficient numbers for study.

We selected plants from a 2-ha area of young regenerating forest, ensuring that they represented four age stages (0.5-5 years old) and the entire height range (up to $8 \mathrm{~m}$ high). Selected individuals were surrounded by other saplings of the same species. Other species of ferns (Dicranopteris linearis), grasses (Phragmites communis, Imperata cylindrica) and lianas together covered less than $25 \%$ of the total leaf area of the stand. Later successional species were absent. It can thus be assumed that competition was mostly among the four selected species.

\section{Measurements}

Measurements on the individuals in the 5-year-old stand (vegetation stage IV) were carried out in September and October of 2004. Light climate, LAI and biomass allocation were determined per individual so that light capture could be calculated. In November 2004 the area was experimentally slashed and burned. After 150 days (spring 2005; vegetation stage I), 50 individuals per species were 
randomly selected from ten plots of $25 \mathrm{~m}^{2}$ each and measured non-destructively (light climate, LAI and biomass allocation). The same saplings were measured again at 330 days (fall 2005; vegetation stage II) and 510 days (spring 2006; vegetation stage III) after the slash and burn treatment. More than one-third of the saplings died during the course of the study due to human-caused factors (not related to the size of individual plants), but care was taken that all individuals included in the data analysis were not disturbed. We analysed data in two ways: (1) using all individuals present at a certain time and (2) using only individuals that survived until stage III. As our results were entirely comparable, we chose to include all individuals for the analyses, with the exception of the growth analysis, which was performed on surviving individuals only.

In vegetation stage IV we established plots of $9 \mathrm{~m}^{2}$, with each plot containing an individual sapling in the centre where light and LAI was measured. Within the $25-\mathrm{m}^{2}$ plots of vegetation stage I, II and III, we created $1-\mathrm{m}^{2}$ subplots to measure light and LAI. All measurements were carried out in the same manner in all vegetation stages, under a uniform overcast sky. The PPFD (400-700 nm) was measured in the centre of each quadrant of each (sub)plot, summing up to four light profiles per target individual. These were averaged per (sub)plot. Light was measured at ground level and at $0.25,0.5,0.75$ and $1 \mathrm{~m}$ above the ground using spherical light quantum sensors and meters (model LI-250; LI-COR, Lincoln, NE). Field testing revealed that light at levels higher up in the canopy could be accurately calculated from these values. Light measurements were carried out simultaneously above the vegetation canopy. The LAI was measured four times in each (sub)plot at ground level from every corner of the (sub)plot facing the centre (model LAI-2000, Plant Canopy Analyser; LI-COR). Vertical leaf area distribution was determined by counting the number and recording the height of leaves touched by a telescopic rod when it was moved up through the vegetation. This maneuver was performed in the centre of each quadrant of a sub(plot).

For individuals in vegetation stage IV, we recorded height up to the highest leaf. Leaf angles of 20 leaves randomly distributed over the tree's crown were measured for six individuals per species. The sapling was harvested, and the leaves were collected per $25-\mathrm{cm}$ layer, whereas stem, branches and petioles were pooled for the whole sapling. Leaf area was measured with a digital photograph (SigmaScan Pro 5.0; SPSS, Chicago, IL). All samples were dried for $72 \mathrm{~h}$ at $70^{\circ} \mathrm{C}$ and weighed. Leaf $\mathrm{N}$ content was analysed with a continuous flow analyser (SKALAR, Breda, the Netherlands) following the Kjeldahl method.

In vegetation stages I, II and III, we measured the following parameters on the saplings: height, leaf angles, length and diameter of stem, branches and petioles and length and width of leaves. Samples to determine leaf N content were taken. To obtain allometric relations between the dimensions and the biomass of above-ground plant parts, we harvested 20 individuals per species in the same height range as the studied individuals. The same dimensions were measured, and the dry weight of stem, branches, petioles and leaves was determined. Dry weights and estimates based on dimensions were correlated, and the function that best described dry weight $\left(r^{2}\right.$ varied from 0.92 to 0.99$)$ was used to calculate the dry weight of the studied saplings.

In March 2005, photosynthesis measurements were carried out using an open gas exchange system (model CIRAS 2; PP systems, Hitchin, UK) equipped with a LED light source. Up to 28 leaves of different ages (young, average and old: related to position on the branch) were selected on different individuals (maximum of three leaves per individual) that were growing outside the plots. Photosynthetic rates were measured early in the morning when stomata were open. Maximum photosynthetic rates were measured at photosynthetic active radiation (PAR) values of $1200-1500 \mu \mathrm{mol} \mathrm{m}{ }^{-2} \mathrm{~s}^{-1}$. In order to determine dark respiration and quantum yield, we varied light from 80 to $0 \mu \mathrm{mol} \mathrm{m}{ }^{-2} \mathrm{~s}^{-1}$ PAR in steps of $10-20 \mu \mathrm{mol} \mathrm{m} \mathrm{m}^{-2} \mathrm{~s}^{-1}$. The $\mathrm{CO}_{2}$ concentration in the chamber was maintained at $370 \mathrm{ppm}$ throughout all measurements.

\section{Model description}

The model used here is almost identical to the one used by Anten and Hirose (2003) and has been described into detail by them. We provide a short description here, including references to the equations used by them. The model simulates plots identical to those used in our study $\left(1 \mathrm{~m}^{2}\right.$ in vegetation stages I-III and $9 \mathrm{~m}^{2}$ in IV) with $25-\mathrm{cm}$ horizontal vegetation layers. The leaf area of target individuals and neighbours are assumed to be randomly distributed in each layer. Instantaneous photosynthesis is calculated as a function of leaf $\mathrm{N}$ content and absorbed photon flux, which in turn is a function of the leaf angle distribution and leaf absorbance of a target individual and the surrounding vegetation. With respect to light capture, two classes of leaves are distinguished: shaded and sunlit (following De Pury and Farquhar 1997). The photon flux captured by the shaded leaf area is calculated by summing the diffuse sky irradiance and the scattered beam irradiance [Eqs. (1)-(5) in Anten and Hirose 2003]. Sunlit leaves receive direct beam and diffuse sky irradiance [Eqs. (6)-(7) in Anten and Hirose 2003]. Since the distribution of diffuse irradiance is incident under various angles, the sky dome is divided into three zones from which diffuse irradiance is calculated, assuming a standard overcast sky (Goudriaan 1977). Three leaf inclination classes are assumed for the calculation of the extinction coefficient for light, following Goudriaan 
(1988) [see Eqs. (3)-(6) in Anten 1997]. The distribution of diffuse light thus calculated corresponded well with our measured light gradients.

A non-rectangular hyperbola was used to characterize the light response of net leaf photosynthesis (Johnson and Thornley 1984) [Eq. (8) in Anten and Hirose 2003]. Light saturated rates of photosynthesis are linearly dependent on leaf $\mathrm{N}$ content per unit leaf area [Eq. (9a) in Anten and Hirose 2003], but dark respiration is assumed to be constant in our study. We used the measured value for the quantum yield, and the curvature factor was set to 0.8 (Hirose et al. 1997).

Calculation of the distribution of light saturated photosynthetic rates in the sapling's crown was carried out as a function of the N distribution (Hirose and Werger 1987). For vegetation stages I-III the calculation deviates from that of Anten and Hirose (2003). Nitrogen content was only measured in the most illuminated leaves in the top of the crown $\left(\mathrm{N}_{0}\right)$ in vegetation stage III. We calculated the $\mathrm{N}$ distribution in the crown $\left(\mathrm{N}_{\text {area }}\right)$ using the equation proposed by Anten (1997): $\mathrm{N}_{\text {area }}=\mathrm{N}_{0}\left(I / I_{0}\right)^{0.4}$ with $I / I_{0}$ indicating the relative light intensity. This equation shows that $\mathrm{N}$ distribution scales with light distribution by a power 0.4 . This equation is based on the mean $\mathrm{N}$ distribution in the various stands reviewed by Anten (1997). No direct N measurements were done for stages I and II. The $\mathrm{N}$ content of young fully exposed leaves in the top layer of the crown of an individual in these stages was assumed to be similar to the $\mathrm{N}$ content in stage III, corrected for the specific leaf area (SLA) of the fully exposed leaves. Nitrogen content further below in the canopy was calculated as already described.

Whole plant carbon gain was calculated by integrating leaf photosynthesis over canopy depth for each layer separately and distinguishing between photosynthesis by shaded and sunlit leaves. These values were then integrated over all layers of the plant [Eqs. (10)-(11) in Anten and Hirose 2003] and over the entire day to obtain the daily photosynthetic rate at the plant level (from sunrise to sunset at the latitude of the study site on the median day of the measurements) (compare Gates 1980). Whole-plant daily light capture was calculated in a similar manner.

Photosynthetic rate per unit above-ground mass $\left(P_{\text {mass }}\right.$, mol $\mathrm{C} \mathrm{g}^{-1}$ day $^{-1}$ ) was calculated by dividing whole-plant daily photosynthesis by the above-ground plant mass. $P_{\text {mass }}$ consists of two components: $\Phi_{\text {mass }}$ and LUE.

$P_{\text {mass }}=\Phi_{\text {mass }} \times$ LUE,

where $\Phi_{\text {mass }}$ is the daily light capture per unit aboveground mass (mol PPFD g ${ }^{-1} \mathrm{day}^{-1}$ ) and LUE is photosynthesis per unit of absorbed light (mol C mol PPFD ${ }^{-1}$ ).

Dividing whole-plant daily light capture by the aboveground mass also gives $\Phi_{\text {mass }}$, and by dividing daily light capture by leaf area, we obtain $\Phi_{\text {area }}$, following Hirose and
Werger (1995). In turn, $\Phi_{\text {mass }}$ is equal to the product of $\Phi_{\text {area }}$ and LAR:

$\Phi_{\text {mass }}=\Phi_{\text {area }} \times \mathrm{LAR}$

where $\Phi_{\text {area }}$ is the daily light capture per leaf area (mol PPFD $\left.\mathrm{m}^{-2} \mathrm{day}^{-1}\right)$ and LAR is the leaf area ratio $\left(\mathrm{m}^{2} \mathrm{~g}^{-1}\right)$.

Leaf area ratio is made up of two components: SLA $\left(\mathrm{m}^{2} \mathrm{~g}^{-1}\right)$ and leaf mass ratio (LMR, $\mathrm{g} \mathrm{g}^{-1}$ ):

$\mathrm{LAR}=\mathrm{SLA} \times \mathrm{LMR}$

Note that LAR and LMR are calculated on the basis of above-ground biomass in this study.

Statistical analyses

In vegetation stage IV, the effect of species on the average values of height, plant mass, SLA, LMR, LAR, $\Phi_{\text {area }}$, $\Phi_{\text {mass }}$, LUE and $P_{\text {mass }}$ were analysed using ANOVA, with post-hoc tests to test for differences among species. We used ANCOVA to test for slope-effects in the relations between SLA, LMR, LAR, $\Phi_{\text {area }}$ and $\Phi_{\text {mass }}$ and individual height.

We created plots after the slash and burn treatment to trace back the saplings in the following measuring period. However, as both plot-effects and individuals-effects may occur in this set-up, we performed the analyses of the saplings using a linear mixed effects model (in the Results, this model is abbreviated as MM).

Average values of the photosynthetic characteristics were analysed using ANOVA with Bonferroni post hoc tests. The increase in photosynthetic rates with light (quantum yield), and the slopes of the $P_{\max }-N_{\text {area }}$ relation were analysed with ANCOVA.

\section{Results}

\section{Canopy characteristics}

Light and LAI distribution in the canopy of each vegetation stage is given in Fig. 1a-d. In vegetation stages I, II and III, the LAI tended to be concentrated near the soil, while in stage IV, it was more evenly distributed throughout the vegetation. The percentage of light reaching the soil was higher in stage II than in stage IV even though the LAI was similar (Table 1). This situation could be related to the fact that leaves were more clustered in stage II than in stage IV and that there was more light coming from the side since the canopy tended to be more open in the younger stage (II) than in the older stage (IV).

\section{Sapling growth}

Of the species analysed, Mallotus microcarpus attained the greatest height (Table 2) and exhibited the fastest increase in 


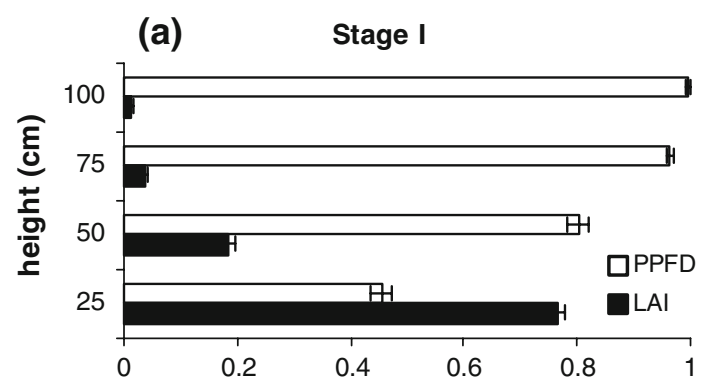

(b)
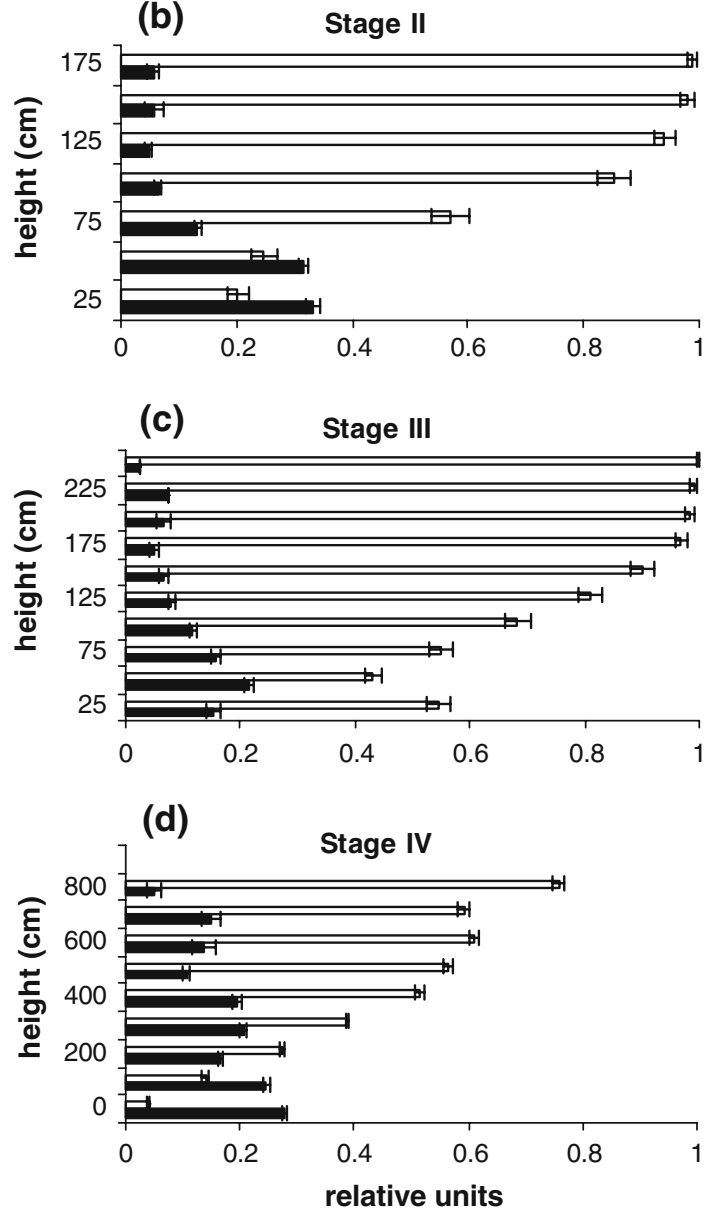

Fig. 1 a-d Light (photosynthetic photon flux density, PPFD) and leaf area index $(L A I)$ distribution in the canopy of four successional secondary forest stages $(n=70-200)$ (for cumulative LAI, see Table 1). Stages I, II and III are stages of the same stand; stage IV is a separate stand. Note that in stage IV, layers of $25 \mathrm{~cm}$ are grouped together into layers of $1 \mathrm{~m}$. Bars: Standard error

height with time (MM, $P=0.003)$ in vegetation stages I, II and III. Its above-ground plant mass was also higher than the mass of the other species (Table 2). Melastoma candidum, which was the smallest species in terms of height, exhibited the highest relative growth rate (RGR) in the period from 150 up to 510 days after the slash and burn treatment (Fig. 2) (MM, $P<0.001$ ) (note that RGR was calculated solely for above-ground biomass). Consequently, size inequalities that were present 6 months after the slash and burn treatment decreased somewhat during the subsequent year. Within species, there was no relation between RGR and individual plant height (MM, $P>0.05$ ). The RGR was also calculated for half-year periods (results not shown), but these values did not significantly differ from the RGR values calculated over a whole year.

Interspecific differences in photosynthetic rates, light capture and use and biomass allocation

Photosynthesis per unit above-ground mass $\left(P_{\text {mass }}\right)$ was calculated as the product of a physiological component, LUE, and a morphological component, light capture per unit above-ground mass $\left(\Phi_{\text {mass, }}\right.$ calculated with the model) [Eq. (1)]. Figure 3a-c shows how these components varied in time and how they determined $P_{\text {mass }}$ from 150 to 510 days in the succession. The greater LAI in stage II relative to stages I and III (Table 1) were not reflected in greater differences between species in $\Phi_{\text {mass }}$ or $P_{\text {mass }}$, indicating that there was no effect of these differences in LAI on interspecific competition (regardless of species height).

Melastoma candidum generally exhibited higher average $P_{\text {mass }}$ values than Mallotus paniculatus and Macaranga denticulata (Fig. 3a) (MM, $P=0.003$ ) but not higher than Mallotus microcarpus. The interspecific differences could not be related to species height. The LUE was higher for Mallotus paniculatus and Melastoma candidum than for the other two species (Fig. 3b) (MM, $P<0.001$ ). This result can be explained by the photosynthetic characteristics of the two species (Table 3): both had low dark respiration. Quantum yield, maximum photosynthetic rate $\left(P_{\max }\right)$ and photosynthetic $\mathrm{N}$ use efficiency (PNUE) were similar for all species. The differences in $\Phi_{\text {mass }}$ between species were not very large (Fig. 3c). Even though Mallotus microcarpus showed the highest $\Phi_{\text {mass }}$ on average (MM, $P<0.001$ ), there was no relation between species height and $\Phi_{\text {mass }}$ which indicated that the degree of asymmetric competition for light was small. $\Phi_{\text {mass }}$ equals the product of $\Phi_{\text {area }}$ (calculated with the model) and LAR [Eq. (2)]. Mallotus microcarpus had a higher $\Phi_{\text {area }}$ on average than the other species (MM, $P=0.009$ ) but a similar LAR (Table 2). The small differences in $\Phi_{\text {mass }}$ between the other species were caused by small differences in LAR, which in turn were caused by differences in SLA (Table 2) [Eq. (2)], with Mallotus microcarpus and Macaranga denticulata having relatively high SLA values (but see below).

Because of the higher LAI and a more than threefold greater vegetation height, one would expect stronger competition between species in stage IV than in the younger stages. $P_{\text {mass }}$ differed between species (Fig. 4a). Mallotus microcarpus had the same value as Melastoma candidum, and these were lower than the values of Mallotus paniculatus and Macaranga denticulata (ANOVA, $P=0.006$ ). There 
Table 1 Characteristics of successional vegetation stages of a Vietnamese forest

\begin{tabular}{lllll}
\hline Age & $\begin{array}{l}\text { Stage I } \\
150 \text { days }\end{array}$ & $\begin{array}{l}\text { Stage II } \\
330 \text { days }\end{array}$ & $\begin{array}{l}\text { Stage III } \\
510 \text { days }\end{array}$ & $\begin{array}{l}\text { Stage IV } \\
5 \text { years }\end{array}$ \\
\hline Mean LAI $\left(\mathrm{m}^{2} \mathrm{~m}^{-2}\right)$ & $3.03 \pm 1.74$ & $5.46 \pm 0.91$ & $3.73 \pm 0.75$ & $5.72 \pm 1.16$ \\
Mean height $(\mathrm{m})$ & $0.61 \pm 0.18$ & $0.99 \pm 0.31$ & $2.4 \pm 0.41$ & $4.71 \pm 1.54$ \\
Light on forest floor $(\%)$ & 45 & 20 & 55 & 3 \\
\hline
\end{tabular}

Stages I, II and III are different successional stages of one stand

LAI, Leaf area index

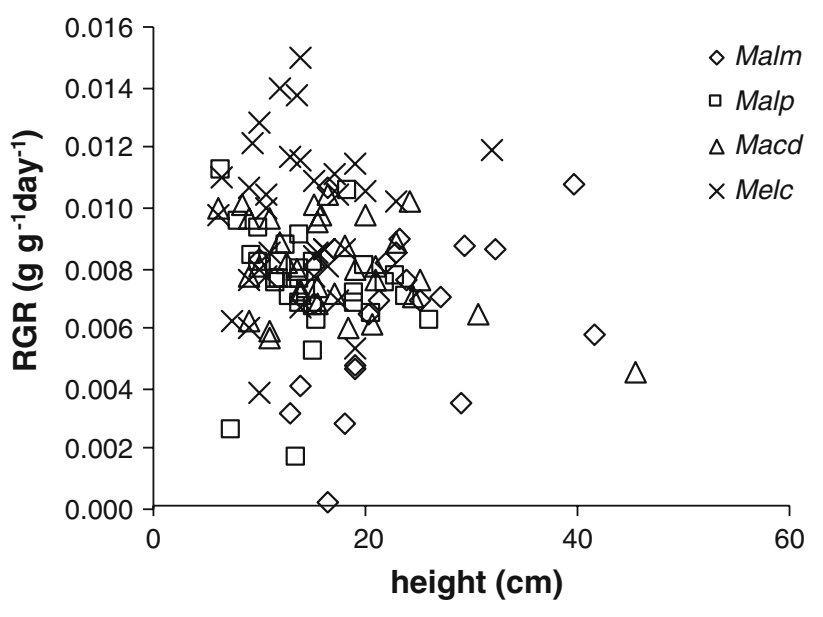

Fig. 2 Relation between above-ground relative growth rate $(R G R)$ and height for four pioneer species calculated for a 360-day study period from 150 to 510 days after the slash and burn treatment. Malm Mallotus microcarpus, Malp Mallotus paniculatus, Macd Macaranga denticulata, Melc Melastoma candidum

was no clear relation between species height and $P_{\text {mass }}$. The LUE was highest for Melastoma candidum (Fig. 4b) (ANOVA, $P<0.001$ ). There were differences in the $\Phi_{\text {mass }}$ values (Fig. 4c) (ANOVA, $P=0.004$ ), with the tallest and the smallest species having similar, relatively low $\Phi_{\text {mass }}$ compared to the species with intermediate height. Values of $\Phi_{\text {mass }}$ were tenfold lower in stage IV than in the younger stages because plants had lower LAR and $\Phi_{\text {area }}$ (Table 2), and values of $\Phi_{\text {area }}$ were on average the same for all species in stage IV (Table 2) (ANOVA, $P=0.558$ ). Consequently, between-species differences in $\Phi_{\text {mass }}$ were caused by differences in biomass allocation (Table 2) [Eq. (2)]. Mallotus microcarpus had a relatively low LMR which caused a low LAR while Mallotus paniculatus had a high SLA and thus a high LAR [Eq. (3)]. Macaranga denticulata and Melastoma candidum had intermediate values for LAR.

Intraspecific differences in light capture and biomass allocation

The data of stages III and IV were used to compare differences in intraspecific competition as these stages differed in LAI, vegetation height and light extinction (Table 1). Stages I and II showed qualitatively the same data with respect to intraspecific competition as stage III, so for clarity we present only the data of stages III and IV.

In stage III, $\Phi_{\text {mass }}$ did not increase with individual height (Fig. 5a, Table 4) (MM, $P=0.130)$, indicating that there was no size-asymmetric competition for light within species. Values of $\Phi_{\text {area }}$ increased with individual height for Mallotus microcarpus and Melastoma candidum (Fig. 5b, Table 4) (MM, $P=0.027$ ) simply due to the fact that taller individuals reached the more illuminated layers of the canopy where they could capture more light. The LMR and SLA decreased when individuals were taller (Table 4), thereby decreasing LAR [Eq. (3)]. The increase in $\Phi_{\text {area }}$ compensated for the loss in LAR; therefore, $\Phi_{\text {mass }}$ remained constant with individual height within all species.

In stage IV, $\Phi_{\text {mass }}$ decreased with individual height for Mallotus paniculatus and Macaranga denticulata (Fig. 5c, Table 4). $\Phi_{\text {area }}$ was not correlated with individual plant height (Fig. 5d, Table 4); apparently individuals had already reached the most illuminated layers of the canopy, so an increase in height did not increase $\Phi_{\text {area }}$. The decrease in $\Phi_{\text {mass }}$ could be attributed to a decrease in LAR with individual height due to concomitant reductions in SLA and LMR (Table 4).

\section{Discussion}

Limited degree of size-asymmetric competition for light

When competition for a resource is asymmetric, larger individuals obtain a disproportionately larger share of the available resource, which in turn can lead to increases in plant size inequalities. In our study, differences in light capture relative to plant size between species were present, but they were relatively small. They were not related to plant size, indicating that the degree of asymmetric competition was very small. This result is in contrast to the general assumption that asymmetric competition for light is important as larger individuals shade shorter ones (see 


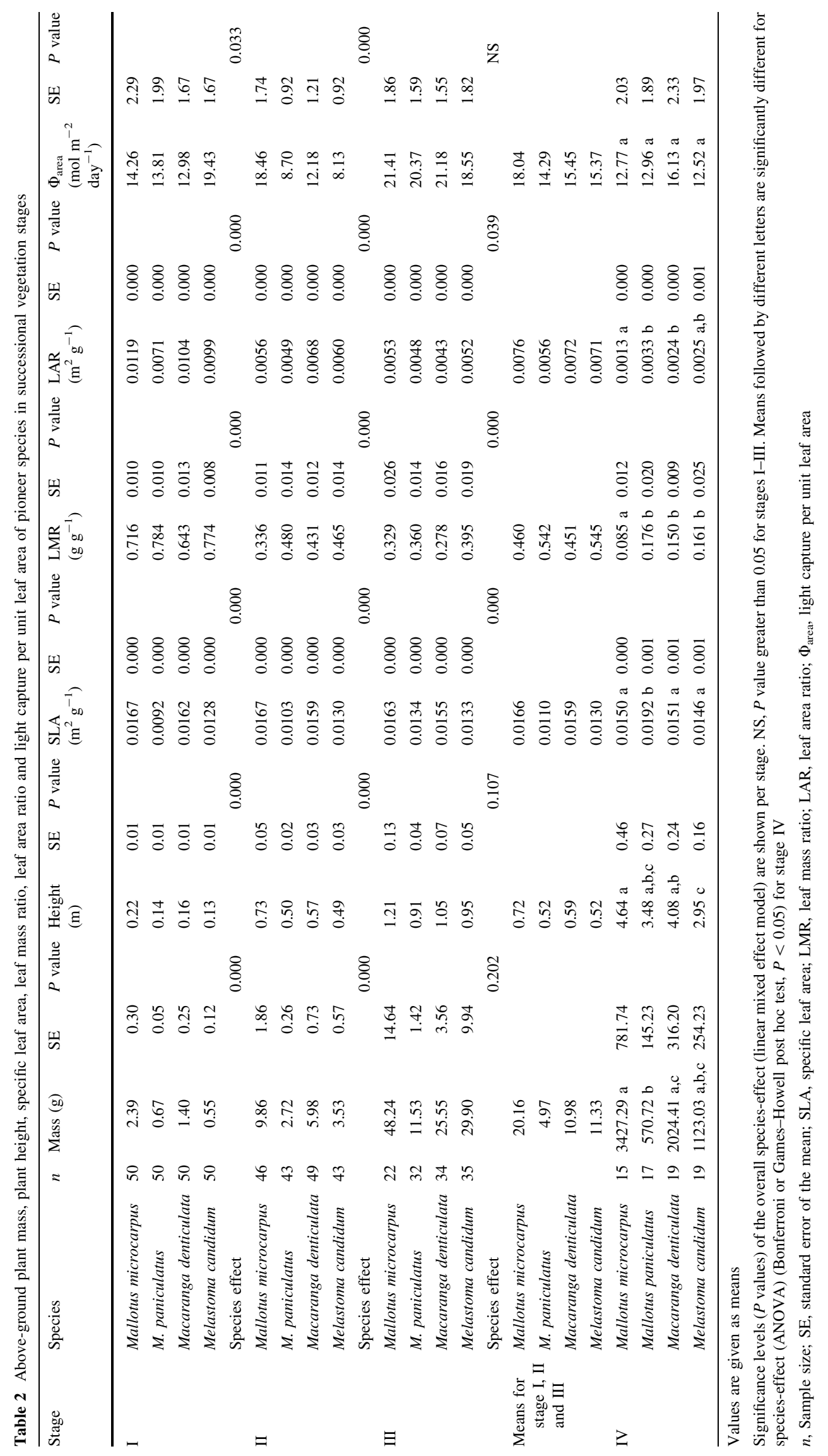



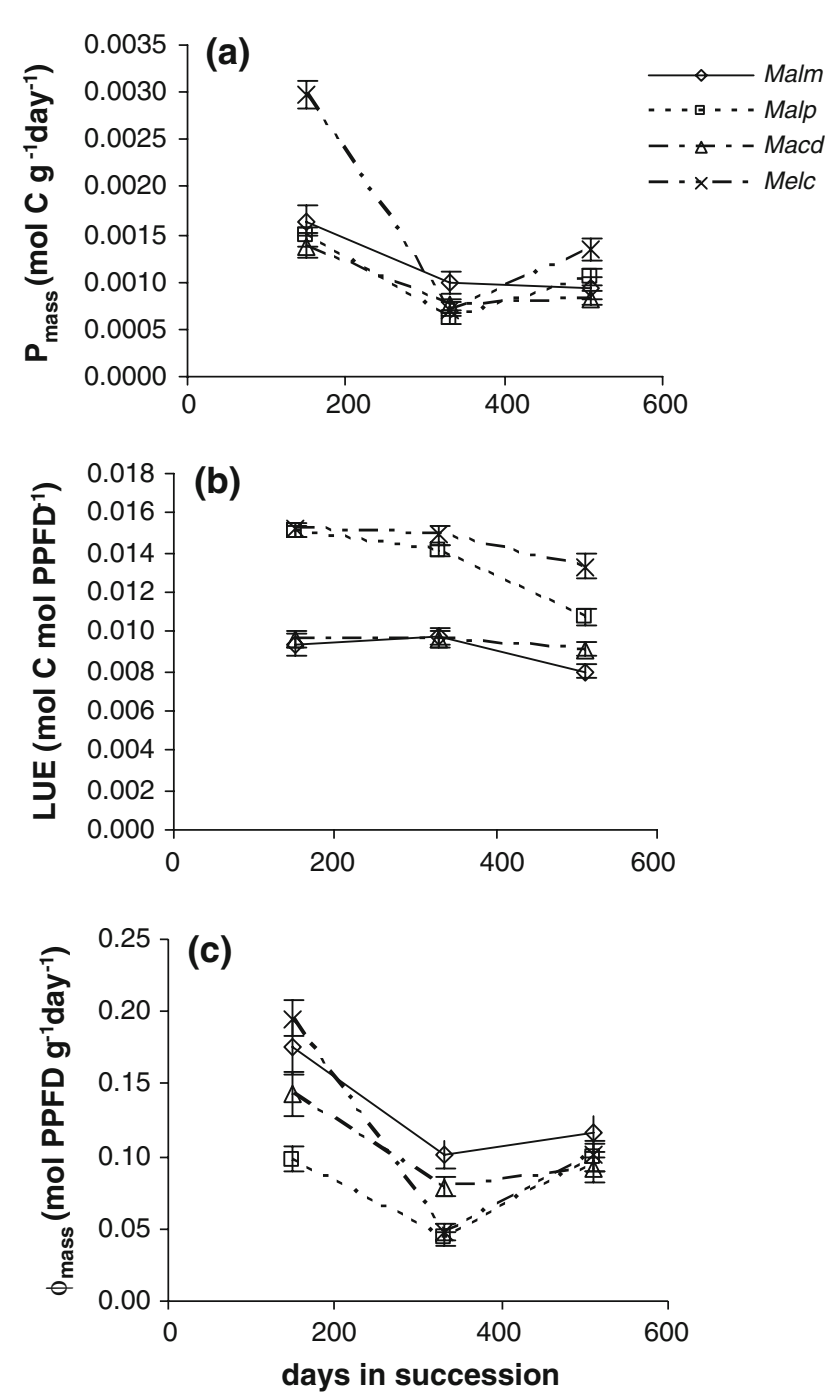

Fig. 3 a-c Photosynthesis per unit above-ground mass $\left(P_{\text {mass }}\right)$, lightuse efficiency $(L U E)$ and light capture per unit leaf area $\left(\Phi_{\text {mass }}\right)$ of saplings during forest succession (150-510 days after the slash and burn treatment). Abbreviations: see Fig. 2. Bars: Standard error

Weiner and Thomas 1986), but it is consistent with the results of several studies on grasslands (Aan et al. 2006; Anten and Hirose 1999; Hirose and Werger 1995) and a secondary forest (Selaya et al. 2007), where a similarity in light capture per unit mass between species of different size was also observed.

Asymmetric light competition was not observed between taller and smaller individuals within one species. This is in contradiction to Anten and Hirose (1998) who suggested that while light competition between species may be size-symmetric, within species it is generally asymmetric. Other researchers have reported that the degree of size-asymmetry in light competition increases with both the height and LAI of a vegetation stand (Aan et al. 2006; Anten and Hirose 1999; Hikosaka et al. 1999). We, however, did not observe such a trend: differences in light capture per unit mass $\left(\Phi_{\text {mass }}\right)$ between larger and smaller plants were not greater in the taller and denser stand (stage IV) than in the younger vegetation stages.

Growth per unit mass was independent of plant size both when comparisons were made among and within species. As a result, the relative height differences between species that were present at 5 months after field abandonment stayed more or less constant during the subsequent 5 years of succession. Thus, the results in this study contradict the notion presented in the literature (Huston and Smith 1987; Van Breugel 2007) that in young secondary forest stands asymmetric competition for light should be the main mechanism shaping secondary forest dynamics. Our study does not preclude, however, that asymmetric competition may become more apparent in later stages of succession. Furthermore, we did not consider below-ground competition, and as this often tends to be size-symmetric (Weiner 1986)—but see Hikosaka and Hirose (2001) where it was found to be asymmetric - it may have contributed to the size-symmetric growth observed by us.

In the only other study that we know of which has quantified light capture relative to plant size and related that to changes in size hierarchies in a secondary tropical forest (the Bolivian Amazon, Selaya 2007), taller species were reported to have grown disproportionately fast compared to smaller ones during the first 3 years of succession (but species were measured simultaneously in stands of different ages). This pattern was not so much related to larger species capturing disproportionately more light but rather to their having higher photosynthetic rates per unit of captured light (LUE). The discrepancy with our results may be related to differences in the overall growth rate of the plants at the two sites: at the Bolivian site, the vegetation reached a height of $1.8 \mathrm{~m}$ on average within the first 6 months after field abandonment and $7.8 \mathrm{~m}$ after 3 years (Selaya 2007), a pattern also observed in another neotropical site (Mexico, Van Breugel 2007); in contrast, in our study in Vietnam, the vegetation only reached $0.6 \mathrm{~m}$ in 5 months and $4.7 \mathrm{~m}$ after 5 years. Our study site was very degraded and probably had poor soil conditions. For the past 25 years it has been repeatedly used as a plantation site for Acacia trees (one cycle takes 5-6 years). In contrast, the sites studied by Selaya (2007) and Van Breugel (2007) were in their first slash and burn agricultural cycle. Thus, as was predicted by Schwinning (1996), the degree of asymmetry in competition may be related to the overall rate of height increment and canopy development in a vegetation stand and not so much to the height or LAI ultimately achieved.

We were able explain well the observed results of the limited occurrence of asymmetric growth and light competition in a mechanistic manner using a canopy photosynthesis model, where photosynthetic rate per unit 
Table 3 Photosynthetic characteristics of pioneer species: quantum yield, light compensation point, dark respiration, maximum photosynthetic rate and photosynthetic $\mathrm{N}$ use efficiency

\begin{tabular}{|c|c|c|c|c|c|c|c|c|c|c|c|}
\hline Species & $n$ & $\begin{array}{l}\text { Quantum yield } \\
(\mu \mathrm{mol} \mathrm{C} \\
\left.\text { PPFD }^{-1}\right)\end{array}$ & SE & $\begin{array}{l}\text { Light compensation } \\
\text { point (PPFD) }\end{array}$ & SE & $\begin{array}{l}\text { Dark respiration } \\
\left(\mu \mathrm{mol} \mathrm{m}{ }^{-2} \mathrm{~s}^{-1}\right)\end{array}$ & SE & $\begin{array}{l}P_{\max } \\
(\mu \mathrm{mol} \\
\left.\mathrm{m}^{-2} \mathrm{~s}^{-1}\right)\end{array}$ & SE & $\begin{array}{l}\text { PNUE } \\
(\mu \mathrm{mol} \mathrm{C} \\
\left.\mathrm{mmol} \mathrm{N}^{-1} \mathrm{~s}^{-1}\right)\end{array}$ & SE \\
\hline $\begin{array}{l}\text { Mallotus } \\
\quad \text { microcarpus }\end{array}$ & $15-23$ & $0.03 \mathrm{a}$ & 0.00 & $46.0 \mathrm{a}$ & 8.4 & $1.0 \mathrm{a}$ & 0.2 & $12.8 \mathrm{a}$ & 1.3 & $0.125 \mathrm{a}$ & 0.011 \\
\hline M. paniculatus & $15-28$ & $0.03 \mathrm{a}$ & 0.00 & $7.4 \mathrm{~b}$ & 2.0 & $0.2 \mathrm{~b}$ & 0.1 & $8.6 \mathrm{a}$ & 0.7 & $0.104 \mathrm{a}$ & 0.007 \\
\hline $\begin{array}{l}\text { Macaranga } \\
\text { denticulata }\end{array}$ & $16-17$ & $0.04 \mathrm{a}$ & 0.00 & $15.5 \mathrm{~b}, \mathrm{c}$ & 3.5 & $0.5 \mathrm{c}$ & 0.1 & $9.8 \mathrm{a}$ & 1.4 & $0.122 \mathrm{a}$ & 0.014 \\
\hline $\begin{array}{l}\text { Melastoma } \\
\text { candidum }\end{array}$ & $10-16$ & $0.04 \mathrm{a}$ & 0.00 & $22.5 \mathrm{c}$ & 2.9 & $0.4 \mathrm{~b}, \mathrm{c}$ & 0.0 & $10.8 \mathrm{a}$ & 1.1 & $0.138 \mathrm{a}$ & 0.009 \\
\hline
\end{tabular}

Values are means

Means followed by different letters are significantly different for species-effect (ANOVA) (Bonferroni post hoc test, $P<0.05$ )

$n$, Sample size; SE, standard error of the mean; $P_{\max }$, maximum photosynthetic rate; PNUE, photosynthetic N use efficiency; PPFD, photosynthetic photon flux density
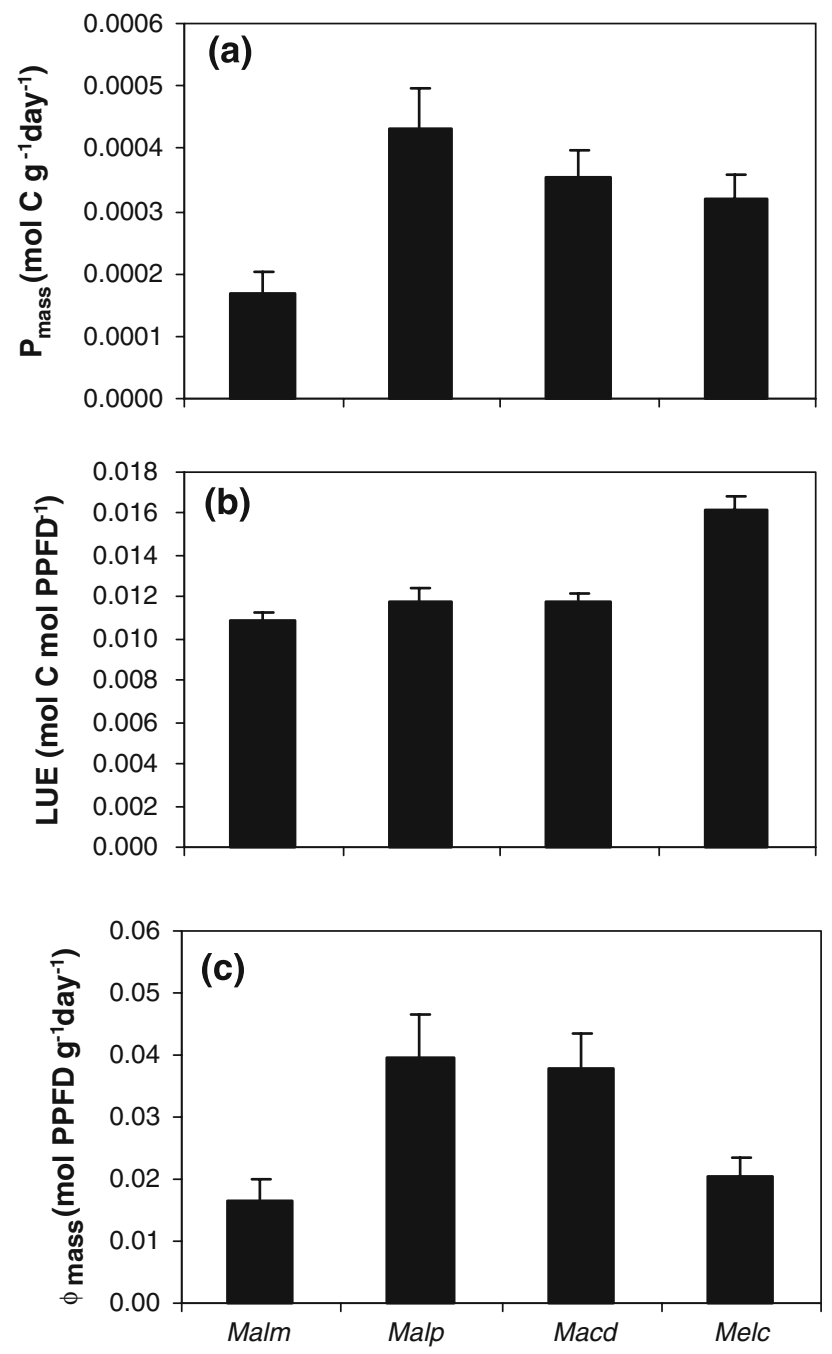

Fig. 4 a-c $P_{\text {mass }}$, LUE and $\Phi_{\text {mass }}$ of pioneer species in stage IV. Abbreviations: see Fig. 2. Bars: standard error mass was used as a proxy for size-dependent growth. The relative growth rate that was observed in the field was strongly correlated with the calculated photosynthetic rates per unit mass for species $\left(r^{2}=0.87\right)$. Photosynthetic rate per unit of mass in turn was analysed as the product of light capture per unit mass, which is mainly determined by morphological plant traits, and LUE, which is largely associated with physiological characteristics of plants (Anten and Hirose 2003). In general, taller plants captured slightly more light per unit leaf area (but not in vegetation stage IV), but due to species differences in LAR, light capture per unit mass, i.e. light-capturing efficiency, was similar for taller and smaller species and within species for taller and smaller individuals. Overall, Melastoma candidum had the highest LUE, but other species were similar to each other. In terms of the leaf physiological traits that determine LUE, species mainly differed with respect to dark respiration and the associated light compensation point. Due to the relatively small differences in LUE and light capture per unit mass, differences in photosynthetic rates per unit mass between species were also small. This was reflected in the stable size hierarchy of the saplings in the field.

Pioneer species differed strongly in functional traits

Pioneers are usually grouped together as one functional group and compared with other functional groups with respect to light requirements (Chazdon 1992; King 1994; Kitajima 1994; Selaya et al. 2007). Implicitly they are therefore assumed to have similar functional traits. This study shows that pioneer species can have quite similar light-capturing efficiencies and photosynthetic rates per unit mass but that they can differ considerably from each 

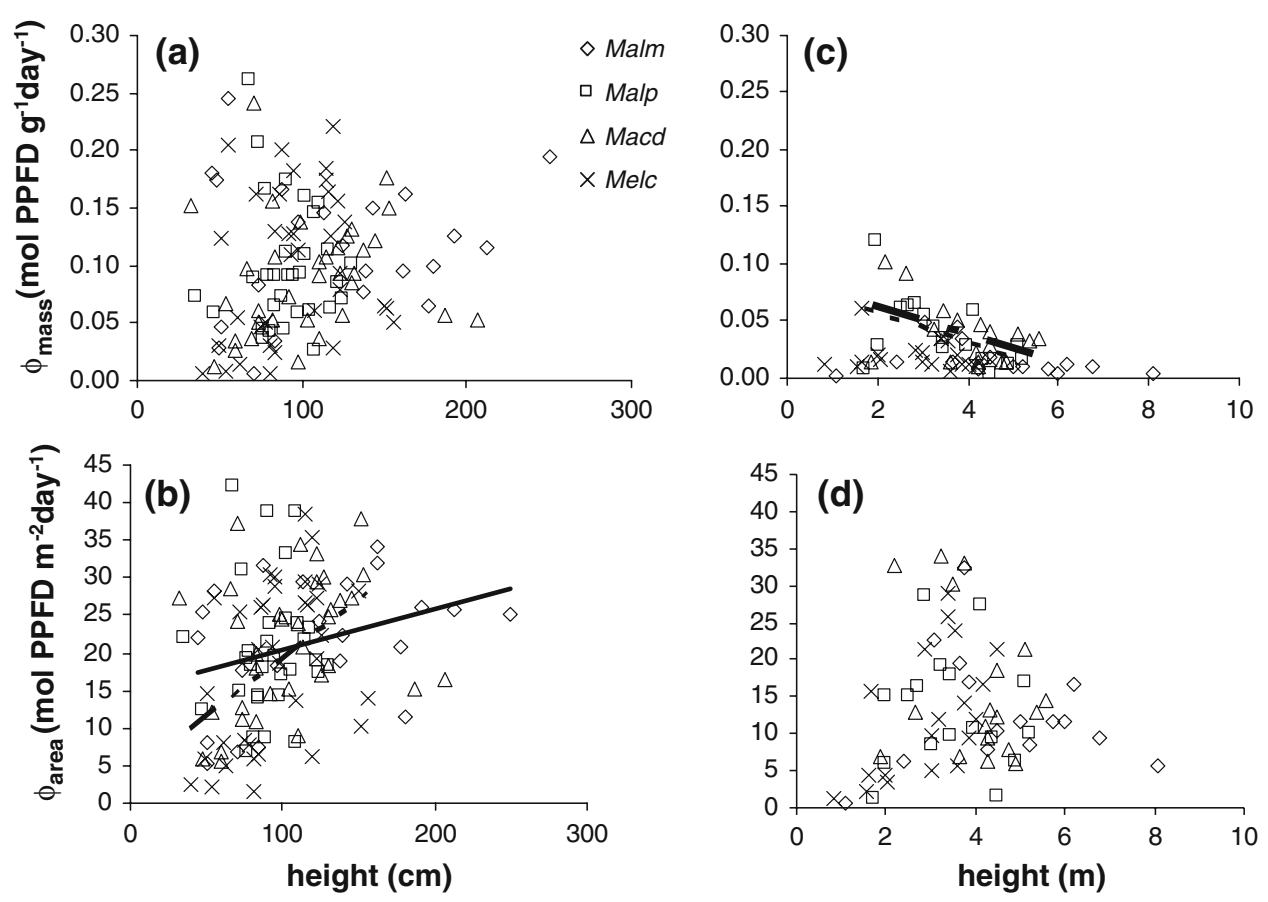

Fig. 5 Relation between $\Phi_{\text {mass }}$ and daily light capture per leaf area $\left(\Phi_{\text {area }}\right)$ and individual plant height in stages III $(\mathbf{a}, \mathbf{b})$ and IV $(\mathbf{c}, \mathbf{d})$. In $\mathbf{b}$ and $\mathbf{c}$ the regression lines indicate a significant relation (b solid line

for Malm, broken line for Melc; c dashed line for Malp, broken line for $M a c d$ ). Abbreviations: see Fig. 2

Table 4 Analysis of covariance (ANCOVA) with light capture per unit leaf area and per unit mass, respectively, specific leaf area, leaf mass ratio and leaf area ratio as dependent variables and plant height as covariate

\begin{tabular}{|c|c|c|c|c|c|c|c|c|}
\hline \multirow[t]{2}{*}{ Stage } & \multirow[t]{2}{*}{ Dependent } & \multirow[t]{2}{*}{ Covariate } & \multicolumn{2}{|c|}{ Slope-effect } & \multicolumn{2}{|c|}{ Height-effect } & \multicolumn{2}{|c|}{ Species-effect } \\
\hline & & & $F$ value & $P$ value & $F$ value & $P$ value & $F$ value & $P$ value \\
\hline \multirow[t]{5}{*}{ III } & $\Phi_{\text {area }}$ & Height & 0.227 & NS & 4.871 & 0.027 & 0.746 & NS \\
\hline & $\Phi_{\text {mass }}$ & Height & 1.014 & NS & 2.340 & NS & 3.015 & 0.035 \\
\hline & SLA & Height & 26.092 & 0.000 & 25.024 & 0.000 & 55.511 & NA \\
\hline & LMR & Height & 2.102 & NS & 4.892 & 0.029 & 3.565 & 0.017 \\
\hline & LAR & Height & 0.374 & NS & 0.314 & NS & 0.177 & NS \\
\hline \multirow[t]{5}{*}{ IV } & $\Phi_{\text {area }}$ & Height & 2.701 & NS & 0.086 & NS & 0.639 & NS \\
\hline & $\Phi_{\text {mass }}$ & Height & 1.932 & NS & 9.021 & 0.004 & 5.702 & 0.002 \\
\hline & SLA & Height & 1.622 & NS & 19.496 & 0.000 & 1.721 & NS \\
\hline & LMR & Height & 16.094 & 0.000 & 57.590 & 0.000 & 14.760 & NA \\
\hline & LAR & Height & 11.781 & 0.000 & 68.344 & 0.000 & 10.702 & NA \\
\hline
\end{tabular}

NS indicates a $P$ value greater than 0.05

NA, Non-applicable; $\Phi_{\text {mass }}$, light capture per mass. For the other abbreviations, see footnotes to Table 2

other when it comes to morphology and physiology, even when congeneric species are compared. The differences between the two Mallotus species were considerable. Mallotus paniculatus initially had an almost twofold lower SLA than M. microcarpus, but its SLA increased in time while that of the other species remained constant. Mallotus microcarpus and M. paniculatus also exhibited the highest and the lowest values, respectively, for light compensation point, dark respiration and $P_{\max }$. The dark respiration and associated light compensation point differed at least fourfold between them.

Melastoma candidum showed the highest RGR, and it could also keep up very well with vegetation height in the sapling stage. Since it is a shrub, its inherent architecture inhibits it from growing tall $(>5 \mathrm{~m})$, but it was able to persist at least in the first 5 years of succession. Melastoma candidum produced many branches that were all directed upwards, and its leaves were placed at the growing tips of 
these branches (also found by Davies and Semui 2006) in the most illuminated layer of the crown, thereby increasing light capture per unit leaf area. More than $70 \%$ of the leaves were placed horizontally, which is also favourable for light capture (Hikosaka and Hirose 1997). Macaranga denticulata, on the contrary, hardly produced branches in vegetation stages I-III, and in stage IV also, branch mass was low compared to that of the other species (results not shown). However, it did produce long petioles, thereby placing the leaves in lighter environments in order to increase light capture per unit leaf area (although this petiole trait is not incorporated in our model). The same phenomenon was observed for its congener Macaranga gigantea (Yamada et al. 2000).

Acknowledgements We would like to thank the staff of Tropenbos International Vietnam for their practical and logistic assistance during the fieldwork and the staff of Bach Ma National Park and the people of Khe Tre village for allowing us to work in the buffer zone of the park. We are also indebted to Dr. Robert Pearcy, Dr. Pieter Zuidema and two anonymous reviewers for their constructive comments on a previous version of this paper. This work was supported by grant W84-577 from WOTRO, the Netherlands. Our experiments comply with the laws in Vietnam and the Netherlands.

Open Access This article is distributed under the terms of the Creative Commons Attribution Noncommercial License which permits any noncommercial use, distribution, and reproduction in any medium, provided the original author(s) and source are credited.

\section{References}

Aan A, Hallik LEA, Kull O (2006) Photon flux partitioning among species along a productivity gradient of an herbaceous plant community. J Ecol 94:1143-1155

Aide TM, Zimmerman JK, Herrera L, Rosario M, Serrano M (1995) Forest recovery in abandoned tropical pastures in Puerto Rico. For Ecol Manag 77:77-86

Anten NPR (1997) Modelling canopy photosynthesis using parameters determined from simple non-destructive measurements. Ecol Res 12:77-88

Anten NPR, Hirose T (1998) Biomass allocation and light partitioning among dominant and subordinate individuals in Xanthium canadense stands. Ann Bot 82:665-673

Anten NPR, Hirose T (1999) Interspecific differences in aboveground growth patterns result in spatial and temporal partitioning of light among species in a tall-grass meadow. J Ecol 87: 583-597

Anten NPR, Hirose T (2003) Shoot structure, leaf physiology, and daily carbon gain of plant species in a tallgrass meadow. Ecology 84:955-968

Bakker JP, Olff H, Willems JH, Zobel M (1996) Why do we need permanent plots in the study of long-term vegetation dynamics? J Veg Sci 7:147-156

Chazdon RL (1992) Photosynthetic plasticity of two rain forest shrubs across natural gap transects. Oecologia 92:586-595

Davies SJ, Semui H (2006) Competitive dominance in a secondary successional rain-forest community in Borneo. J Trop Ecol 22: $53-64$
De Pury DGG, Farquhar GD (1997) Simple scaling of photosynthesis from leaves to canopies without the errors of big-leaf models. Plant Cell Environ 20:537-557

Denslow JS (1987) Tropical rainforest gaps and tree species diversity. Annu Rev Ecol Syst 18:431-451

Ellsworth DS, Reich PB (1996) Photosynthesis and leaf nitrogen in five Amazonian tree species during early secondary succession. Ecology 77:581-594

Finegan B (1984) Forest succession. Nature 312:109-114

Ford ED (1975) Competition and stand structure in some even-aged plant monocultures. J Ecol 63:311-333

Gates DM (1980) Biophysical ecology. Springer, New York

Goudriaan J (1977) Crop micrometerology: a simulation study. Wageningen, the Netherlands

Goudriaan J (1988) The bare bones of leaf-angle distribution in radiation models for canopy photosynthesis and energy exchange. Agric For Meteorol 43:155-169

Hikosaka K, Hirose T (1997) Leaf angle as a strategy for light competition: optimal and evolutionarily stable light-extinction coefficient within a leaf canopy. Ecoscience 4:501-507

Hikosaka K, Hirose T (2001) Nitrogen uptake and use by competing individuals in a Xanthium canadense stand. Oecologia 126: 174-181

Hikosaka K, Sudoh S, Hirose T (1999) Light acquisition and use by individuals competing in a dense stand of an annual herb, Xanthium canadense. Oecologia 118:388-396

Hiremath AJ (2000) Photosynthetic nutrient-use efficiency in three fast-growing tropical trees with differing leaf longevities. Tree Physiol 20:937-944

Hirose T, Werger MJA (1987) Maximizing daily canopy photosynthesis with respect to the leaf nitrogen allocation pattern in the canopy. Oecologia 72:520-526

Hirose T, Werger MJA (1995) Canopy structure and photon flux partitioning among species in a herbaceous plant community. Ecology 76:466-474

Hirose T, Ackerly DD, Traw MB, Ramseier D, Bazzaz FA (1997) $\mathrm{CO}_{2}$ elevation, canopy photosynthesis, and optimal leaf area index. Ecology 78:2339-2350

Hirsch P (1997) Deforestation in southeast Asia. Geodate 10:5-8

Huston M, Smith T (1987) Plant succession: life history and competition. Am Nat 130:168-198

Johnson IR, Thornley JHM (1984) A model of instantaneous and daily canopy photosynthesis. J Theor Biol 107:531-545

King DA (1994) Influence of light level on the growth and morphology of saplings in a Panamanian forest. Am J Bot 81:948-957

Kitajima K (1994) Relative importance of photosynthetic traits and allocation patterns as correlates of seedling shade tolerance of 13 tropical trees. Oecologia 98:419-428

Orians GH, Pfeiffer EW (1970) Ecological effects of the war in Vietnam. Science 168:544-554

Peña-Claros M (2003) Changes in forest structure and species composition during secondary forest succession in the Bolivian Amazon. Biotropica 35:450-461

Schwinning S (1996) Decomposition analysis of competitive symmetry and size structure dynamics. Ann Bot 77:47-58

Schwinning S, Weiner J (1998) Mechanisms determining the degree of size asymmetry in competition among plants. Oecologia 113:447-455

Selaya NG (2007) Sprinting, climbing and persisting: light interception and carbon gain in a secondary tropical forest succession. $\mathrm{PhD}$ thesis. Utrecht University, Utrecht

Selaya NG, Anten NPR, Mathies M, Oomen RJ, Werger MJA (2007) Aboveground biomass investments and light interception of tropical forest trees and lianas early in succession. Ann Bot 99:141-151 
Swaine MD, Hall JB (1983) Early succession on cleared forest land in Ghana. J Ecol 71:601-627

Tran T, Ziegler S (2001) Utilization of medicinal plants in Bach Ma National Park, Vietnam. Med Plant Conserv 7:3-5

Uhl C (1987) Factors controlling succession following slash-and-burn agriculture in Amazonia. J Ecol 75:377-407

Van Breugel M (2007) Dynamics of secondary forests. PhD thesis. Wageningen University, Wageningen

Weiner J (1986) How competition for light and nutrients affects size variability in Ipomoea tricolor populations. Ecology 67: $1425-1427$
Weiner J (1990) Asymmetric competition in plant populations. Trends Ecol Evol 5:360-364

Weiner J, Thomas S (1986) Size variability and competition in plant monocultures. Oikos 47:211-222

Werger MJA, Hirose T, During HJ, Heil GW, Hikosaka K, Ito T, et al (2002) Light partitioning among species and species replacement in early successional grasslands. J Veg Sci 13:615-626

Yamada T, Okuda T, Abdullah M, Awang M, Furukawa A (2000) The leaf development process and its significance for reducing self-shading of a tropical pioneer tree species. Oecologia 125:476-482 